\title{
ESTUDIOS GENERALES: UNIVERSIDAD DENTRO DEL TECNOLÓGICO*
}

Carlos de la Isla**

Gracias por haberme invitado a recordar, a revivir el pasado trascendente.

Hace casi 34 años fui invitado por el profesor José Ramón Benito a participar en la labor educativa del ITAM. Él coordinaba entonces, creo que con calidad y lucidez, lo que podría llamarse un renacimiento del Departamento de Estudios Generales.

Mi primer impulso fue de resistencia, porque ya tenía una fuerte carga académica en la UNAM y en el IPN. El profesor Benito amablemente insistió. Recuerdo entonces que pregunté sobre la real, auténtica y razonable libertad de cátedra y sobre los objetivos y filosofía educativa del ITAM. El profesor Benito pronto me aseguró una entera libertad de cátedra y poco después me proporcionó los otros documentos.

Sobre el gran privilegio de la libertad de cátedra responsable siento la necesidad de decir que durante estos casi 34 años de docencia en el ITAM, nunca y en ninguna forma se me ha limitado o acosado. Pienso que esto honra grandemente a esta Institución, porque ciertamente no he sido ni sumiso, ni servil. Por el contrario, he mantenido una actitud crítica y sincera de acuerdo a mis convicciones.

* Esta conferencia se llevó a cabo en el auditorio Raúl Baillères, ITAM, el 23 de febrero del 2006, con motivo de una de las celebraciones, "Viejos recuerdos", por los 60 años de vida académica en el ITAM.

** Departamento Académico de Estudios Generales, ITAM. 
Tenía necesidad de conocer los objetivos y la filosofía educativa del ITAM, porque no hacía mucho tiempo había estado presente, junto a miles de universitarios, aquel dos de octubre en Tlatelolco gritando: "Dignidad, libertad, universidad" hasta que las balas asesinas acallaron el inmenso grito. Lo excelente de ese movimiento del 68 fue el apasionado reclamo: exigimos ser tratados como personas no como mercancías. Aquella experiencia de Tlatelolco afirmó mi determinación de sumarme a los pocos que luchan por la dignidad de la universidad y de la educación.

En los documentos de la filosofía educativa del ITAM leí que esta Institución se propone cultivar los valores humanos fundamentales: dignidad, libertad, justicia, verdad... que su formación exige el compromiso con una sociedad más libre, más justa, más humana, compromiso con la transformación de esta sociedad de las infinitas carencias y de las monstruosas desigualdades.

Como constitutivo esencial del gran proyecto educativo se pensaron las materias de los Estudios Generales, que merecieron la creación de un Departamento, con la inmensa responsabilidad de proporcionar a los estudiantes los mejores elementos para la edificación de la parte más

102 importante de todo proyecto educativo, que es la formación humana que pretende ser integral.

Como casi todos ustedes saben, el programa de Estudios Generales, del que se ha dicho que es la universidad dentro del tecnológico por sus contenidos de universalidad y su estudio desde la perspectiva general (Studia Generalia), consiste en siete materias obligatorias para todos los estudiantes.

Hablo de los Estudios Generales porque en la historia del ITAM han sido una de sus columnas más fuertes y, tal vez, un indispensable distintivo de su calidad educativa.

Los Estudios Generales son una gran oportunidad, un gran medio para la educación del hombre humano. Allí está la fértil y fecunda llanura de cosmovisiones para que la inteligencia se alimente, para que se ejercite en la admiración, contemplación y valoración de las extraordinarias construcciones de conceptos de vida para la vida. 
Tres cursos de Ideas e Instituciones Políticas y Sociales, Ideas de la Civilización Occidental, todas ellas sembradas en su tiempo. Es el gran ejercicio para que la mente conozca, compare, se adhiera o rechace, y para que el estudiante y el maestro se nutran y puedan llegar a generar sus propias ideas que son el móvil de la existencia.

Estos cursos, tomándolos en vivo, generan espontáneamente la pasión por la verdad, por la justicia, por la grandeza, diferencia primordial en la educación del hombre humano. Aquí pueden descubrirse también las perspectivas ilimitadas de la visión que modifica el mundo y que percibe o descubre los caminos de transformación.

Allí también, en los Estudios Generales, están los más graves problemas de nuestra civilización para transitar continuamente de las ideas a la vida y a los problemas de la vida. Desde las ideas los problemas adquieren otras dimensiones; se conocen mejor, se aprecian mejor sus angustias, urgencias y obscuridades. Excelente propósito en un mundo de sombras y mentiras en el que se imponen dicciones, visiones e interpretaciones de todo lo que sucede para imponerle dirección, fin y conveniencia.

La historia sociopolítica de México es, en el conjunto, una materia muy especial, porque emplea las ideas estudiadas, porque aporta sus propias ideas, y éstas son el mejor instrumento para el análisis crítico de los hechos históricos, tantos de ellos también problemas. Y siempre auxiliados por la maestra historia, que por menospreciarla y desplazarla de la memoria, México ha sufrido terribles destrucciones, agresiones y ofensas.

La intención de ordenar cinco materias de Problemas e Ideas antes de los cursos sobre México es evidente. Clara preparación, en lo que ya en sí es fin importante, para el estudio más fuerte, más urgente sobre el prójimo, lo próximo, nosotros todos.

En ese sentido deberían considerarse los Problemas de la Realidad Mexicana Contemporánea, la materia, el curso más importante de todas las carreras, si hemos de tomar en serio el gran objetivo institucional de colaborar en la construcción de una sociedad más libre, más justa, más humana. 
Todas las materias y cursos del Departamento están dirigidos al ser mejor de las personas: al desarrollo del pensamiento crítico, de la imaginación y creatividad, a la afirmación del compromiso social $\mathrm{y}$ al cultivo de esa cualidad indispensable para el crecimiento de una personalidad robusta.

Me refiero al cultivo de la pasión. Me refiero al impulso vibrante, a la energía vital, a la voluntad arriesgada, a la determinación inquebrantable. Me refiero a la pasión en que Hegel pensaba cuando decía: "Nada grande se ha hecho en este mundo sin pasión"; es la pasión de la que habla Castoriadis cuando afirma que la revolución por la democracia ya es imposible, porque ésta requiere pasión por la libertad, por la igualdad, pasión por la justicia y por la tolerancia. Y ahora la energía del démos está invertida en aprobar sin molestias las asignaturas del hedonismo en la escuela del gozoso placer sin estridencias.

Se necesita la pasión que se propone lo que para el mundo parece imposible con la energía que desborda las medidas del mundo de medidas. Pasión por ideales aún inalcanzables; pasión por la verdad que desprecia las mentiras del mundo de mentiras; pasión por la justicia que no soporta el uso de personas convertidas en ganancias; pasión para condenar la sociedad que aprecia más las cosas muertas que las dolencias vivas; pasión para combatir la demencia del amontonamiento del poder sin rostro, que ha sobrepuesto esclavitudes, iniquidades y aniquilación de los encantos de la vida humana; pasión por las alturas y grandezas para despreciar las mediocridades miserables. Sin esta pasión, como esencia educativa, a nada de lo grande que requiere el mundo se podrá aspirar. Eliminada esta pasión del proceso educativo todo terminará en hombres de cabezas uniformes, de pensamientos cortados a la medida, valiosos y funcionales, para una sociedad desabrida de la política de comedia y de caricatura llagada, de la economía que sigue demostrando sus verdades numéricas en el pizarrón de las desigualdades mortales; en una sociedad aburrida que consume la belleza de los días en el juego de los gozos y placeres de las ofertas, demandas y utilidades. 
Sin esta pasión, la educación no vale la pena de ser vivida, no vale la pena ni de ser pensada.

Conocidos los fines y medios institucionales no dudé más sobre mi incorporación a la tarea educativa del ITAM. Debo decir que encontré una comunidad de profesores y estudiantes pequeña. Todos nos conocíamos y puedo afirmar que todos nos estimábamos.

En esta época la atención y el respaldo del Dr. Alberto Baillères fueron especialmente extraordinarios porque el ITAM estaba muy lejos de ser económicamente autosuficiente y él nunca permitió que hubiera carencias o limitaciones. En ese tiempo discurría el gobierno breve pero firme e inteligente del Lic. Antonio Carrillo Flores; breve porque fue invitado por el Secretario de las Naciones Unidas a organizar la $2^{\mathrm{a}}$ semana internacional de demografía.

Lo sucedió el Lic. Javier Beristáin Iturbide quien fortaleció las estructuras y programas existentes, impulsó el crecimiento cuantitativo y cualitativo, organizó nuevas carreras, superó los graves obstáculos para el cambio de Marina Nacional a San Ángel, realizó la estructura pensada para el crecimiento vertical en Santa Teresa. Por supuesto, con apoyo de Don Alberto Baillères y de un buen número de miembros de la comunidad incluido el personal de servicio; tal vez lo que caracterizó su rectoría fue su claridad en la planeación, determinación en sus decisiones y su relación con toda la comunidad que invitaba más a la amistad que a la sumisión.

Sobre los estudiantes de los tiempos que comentamos sólo una alusión global: eran buenos estudiantes. Muchos de ellos realizan actividades relevantes en la sociedad. Varios estudiantes de entonces son autoridades actualmente en el ITAM, entre ellos, el Dr. Arturo Fernández, y si pasamos a tiempos anteriores, el Sr. Baillères, Presidente de la Junta de Gobierno y, otros miembros de la Junta son, honrosamente egresados del ITAM. 
CITAM Derechos Reservados.

La reproducción total o parcial de este artículo se podrá hacer si el ITAM otorga la autorización previamente por escrito. 